\title{
Utilization of Family Planning Services and Influencing Factors Among Women of Child Bearing Age in Assosa District, Benishangul Gumuz Regional State, West Ethiopia
}

\author{
Muluwas Amentie $^{1,2}$, Muluemebet Abera ${ }^{2}$, Misra Abdulahi ${ }^{2}$ \\ ${ }^{1}$ Department of Nursing, Faculty of Health Sciences, Assosa University, Assosa, Ethiopia \\ ${ }^{2}$ Department of Population and Family Health, College of Public Health and Medical Sciences, Jimma University, Jimma, Ethiopia
}

Email address:

muluwas12@gmail.com (M. Amentie),muluemebet.abera@ju.edu.et (M. Abera),misra_ab@yahoo.com (M. Abdulahi)

\section{To cite this article:}

Muluwas Amentie, Muluemebet Abera, Misra Abdulahi. Utilization of Family Planning Services and Influencing Factors Among Women of Child Bearing Age in Assosa District, Benishangul Gumuz Regional State, West Ethiopia. Science Journal of Clinical Medicine.

Vol. 4, No. 3, 2015, pp. 52-59. doi: 10.11648/j.sjcm.20150403.11

\begin{abstract}
Background: Nearly all (99\%) of maternal death occur in the developing countries. However, family planning (FP) could prevent as many as one in every three maternal deaths by allowing women to delay motherhood, space birth, avoid unintended pregnancies and abortion and stop childbearing when they reached their desired family size. Objective: To assess utilization of family planning services and influencing factors among women in Assosa District. Methods: A community based cross sectional study was conducted from May $17-31,2012$ on the selected samples of 536 women who had at least one delivery in the five years prior to the study using simple random sampling technique. Structured questionnaire, FGD and indepth interview guide were used to collect data. Data were analyzed by using SPSS version 16.0. Binary logistic regression was used to determine the association between dependent and independent variables. Results: Out of the 525 study subjects $339(64.6 \%)$ women were currently using any method of contraceptive. Factors influencing utilization of family planning services were attending grade 7 and above $[\mathrm{AOR}=2.19,95 \% \mathrm{CI}$ : $1.11,4.33]$, being knowledgeable on family planning service $[\mathrm{AOR}=3.9,95 \% \mathrm{CI}: 1.36,8.48]$, having favorable attitude towards family planning service $[\mathrm{AOR}=2.16,95 \% \mathrm{CI}: 1.45,3.23$ ] and availability of family planning service $[\mathrm{AOR}=4.33,95 \% \mathrm{CI}$ : $1.5,12.46]$. Conclusion: This study revealed that family planning services were relatively better; they are still low as compared to national HSDP IV target. Educational status, knowledge on family planning, attitude towards family planning services and availability of family planning services were identified as factors affecting current utilization of family planning service. Providing IEC and house-hold level discussion on the important of family planning service utilization in the district is recommended.
\end{abstract}

Keywords: Family Planning Service, Health Service Utilization, Factors, Assosa, Benishangul Gumuz

\section{Introduction}

The child bearing functions of women, especially in developing countries, have been granted as a normal or routine process. Yet these valued and precious parts of life are among the most hazardous experiences that women often engage in without being aware of the risks or dangers that they are in (1).

Family planning (FP) could prevent as many as one in every three maternal deaths by allowing women to delay motherhood, space birth, avoid unintended pregnancies and abortion and stop childbearing when they reached their desired family size (2). Evidence suggests that more than half of all couples in the developing countries are using family planning to delay, space or limit future pregnancies, yet the need for FP keeps increasing as the number of women of reproductive age continues to grow. An estimated 137 million women worldwide have unmet need for FP, that is, they are not using any method and report that they want to avoid pregnancy (3).

In Kenya, the national contraceptive prevalence rate has stagnated at $39 \%$ and many women have limited access to FP during the immediate postpartum period. More than $27 \%$ of 20-29 years old women had less than two years between their last two pregnancies. According to 2003 DHS in Kenya, 23 percent of births are at intervals of less than 24 months; these short intervals increase the risk of adverse prenatal outcomes. Many of these births are unintended. An analysis of the 2003 
Kenya DHS found that $68 \%$ of postpartum women had an unmet need for FP during the first year $(4,5)$. Only $23 \%$ women using family planning methods integrating with other health services during and after pregnant which helps to increase access to and use of contraception, thereby reducing unmet need and preventing unintended pregnant (5).

Ethiopian Demographic and Health Survey (EDHS-2005) revealed that knowledge of contraception has remained consistently high in Ethiopia over the past five years with $88 \%$ of currently married women having heard of at least one method of contraception. However, actual contraceptive practice among women of reproductive age group remained very low (6).

In Addis Ababa, percentage distribution of women with seeking behaviour of family planning services was $62.5 \%$ but in Benishagul Gumuz regional state, uptake of family planning services is $27 \%(6,7,8)$. In Benishangul Gumuz regional state as the figure indicates there was low utilization of family planning services. Even though, utilization of family planning services is affected by a multiple factors. Therefore, an attempt was made in this study to assess the status of family planning service uptake and important factors that affect women to use family planning services.

\section{Methods and Materials}

Community based cross sectional study design was conducted employing both quantitative and qualitative methods of data collections to assess the status of family planning services uptake and influencing factors among women in child bearing age in Assosa District, Assosa Zone, Benishangul Gumuz Regional state, Western Ethiopia. Assosa District is one of the twenty woredas found in Benishangul Gumuz regional State. Assosa town is the capital city of Benishangul Gumuz Regional State. Assosa District is located $676 \mathrm{kms}$ from West of Addis Ababa (Capital City of Ethiopia), $230 \mathrm{kms}$ from Grand Ethiopian Renaissance Dam and 96 km Ethio-Sudan boarder.

The source populations were all women living in Assosa District and had at least one delivery in the five years period preceding the survey. For quantitative method: the study populations were women selected from source population. However, for qualitative method: the study population was the part of community members in the study area such as women in child bearing age groups, community leaders, religious leaders, husbands, health workers and health extension workers. Inclusion criteria were women who had at least one delivery in five years preceding the survey; if women have more than one delivery, the most recent one was selected; permanent residents of the kebeles were selected. However, exclusion criteria: women who had hearing or other disabilities hindering communication; women who were pregnant during the time of the survey even if they had at least one previous delivery.

Sample size was calculated using two population proportion formulas. Therefore, the sample size was calculated for each factors and magnitude of family planning services use and the optimum sample size was taken which is calculated for institutional delivery services because it highest of all sample size determined and this research is the continuation of institutional delivery utilization. So that the sample sizes was 134 for urban and 402 for rural women to be selected considering a design effect of two for the variation due to clustering and non-response rate of $10 \%$. The total calculated sample size was 536 women. For qualitative data, the sample size was purposively determined which result 29 key informative for in-depth interview and 10 FGD were selected to supplement the quantitative data.

Sampling technique for the quantitative data; multi-stage sampling technique was employed. First, the four urban and seventy four rural kebeles were listed from which a total of ten kebeles ( 1 urban and 9 rural) were selected using simple random sampling technique. Secondly, the numbers of households living in the area were recorded; the probability of being included in the sample was proportional to the total number of household residing in each kebele. Assuming every household was to host at least one woman who gave birth in the last five years, households were taken as a final sampling unit. Out of the one sampled urban kebeles, a total of 134 households were selected. Also from the nine sampled rural kebeles, a total of 402 households were selected using simple random sampling techniques. Households that had more than one eligible woman, interview was done by selecting one of them using lottery method. Revisit of three times was made in case where eligible respondents were not available at the time of the survey before considering as nonrespondent.

Sampling technique for qualitative data; a total of ten FGDs were conducted (one FGD having 8-12 individuals: 3FGD for women in child bearing age, 2FGD for husbands, 3FGD for religious and community leaders, and 2FGD for health workers. For in-depth interview purposively selected 29 key informants were interviewed. Ten health workers (one from each kebele), $9 \mathrm{HEWs}$ (one from each of the rural kebeles having HEW) and 10 community leaders (one from each kebele) were interviewed. In order to minimize bias, those who participated in FGDs and in-depth interviews were excluded from participating in quantitative study.

Data collection instruments for quantitative method: structured questionnaire was prepared in English and translated to Amharic language and then back translated to English by different peoples. For qualitative method: for the qualitative part, discussion guide was prepared in English and discussions were made in local languages. Tape record was used at the same time. Interview guide was prepared in English and used for in-depth interview of key informants. Both discussion guide and interview guide were not translated in to Amharic because they are moderated and collected by principal investigator and experienced nurse.

Data collection process for quantitative method: ten female data collectors, who were health extension workers and could speak local languages like Bertegna, Afan-oromo and Amharic, were used. For supervision four nurses having Diploma were selected from Assosa District Health Office, 
Selga 22 Health Center and Abramo Health Centre. Both the interviewers and supervisors were given two days training before the actual work about the study. Practical exercise was made through peer interviewer.

Pre-test was carried out on $27(5 \%)$ of the sample size in two of the kebele in Assosa district which were outside of the selected kebeles that has similar socio-demographics characteristic with the people in both urban and rural kebeles. After completing pre-test, discussion was made with supervisors and data collectors. Then, the data were collected using house-to-house interview questions.

During the actual data collection, supervisors were assigned for the data collector. The supervisors checked the activities of each data collectors by walking with them in each kebele and sometimes-random spot-checking of the households were made to ensure reliability of the data. Each night the supervisors checked all the filled questionnaires for completion, clarity and proper identification of the respondents. Then, the principal investigator randomly checked $10 \%$ of the supervisors' work each day for completeness and relevance. Incomplete and unclear questionnaires were returned back to the interviewers to the next morning to get it corrected. For qualitative method: the principal investigator moderated the discussion of the male groups while the female groups were moderated by an experienced female nurse with diploma holder. Two senior nurses with diploma holder were took a note during the discussion. Each discussion had a tape recorded and finally the conversation was transcribed verbatim after each session.

Data processing and analysis for quantitative method: the collected data were coded, entered, cleaned and analyzed by using SPSS Window version 16.0. Descriptive statistics was calculated for all variables. In bi-variate analysis crude odds ratio and confidence interval were determined to select candidate variables for multivariate analysis at the level significance $(p<0.05)$. Binary and multivariate logistic regressions were used to determine the adjusted odds ratio and corresponding $95 \%$ confidence interval. A maximum likelihood estimate of the independent effect of the predictor variables was used to see the level of significance. The strength of association was interpreted using the adjusted odds ratio and $95 \%$ CI. The criteria for statistical significance were set at $p<0.05$. For qualitative method: data of qualitative method were translated in to English, organized in narrative forms in congruent with the respondents' own words on the same day and analyzed by thematic frame work analysis.

Data quality was controlled by designing structured questionnaire. Interviewers were recruited and trained for two days. Pre-test was carried out for both tools. Two day training was given for data collectors, supervisors, and FGD moderators. The collected data was examined for completeness and internal consistency each day by supervisors. Strict/regular supervision and tape recording of FGD process were also additional quality control methods

The study was conducted after approval of the research proposal by ethical review committee and the survey was commenced after written consent obtained from Benishangul Gumuz Regional State Health Bureau to the respective offices. In turn the Assosa district Administration Office and Assosa Town Administrative Office wrote a letter to study kebeles to get permission and collaboration. Oral consent and written consent were obtained from each interviewee for their agreement to participate in the study. Interviews were conducted in private place. However, the women were assured that neither a 3rd party nor her husband will have access to their responses. Privacy, anonymity and confidentiality were maintained throughout the process of the study by avoiding identity.

\section{Results}

\subsection{Socio-Demographic Profiles}

A total 525 women who gave birth within five years before the survey, were interviewed making a response rate of $97.9 \%$. Three-quarter $(75.0 \%)$ of the respondents were from rural area. Majority $433(82.5 \%)$ women were in the age group 20 and 34 years. Regarding ethnicity 303(57.7\%) of women were Berta and 388(73.9\%) of women were Muslims by religion. Twenty one (16\%) of urban women and 264 $(67.0 \%)$ of rural women were unable to read and write. Regarding marital status, $116(88.5 \%)$ of urban women and $360(91.4 \%)$ rural women were married. Concerning occupational status, more than half $74(56.5 \%)$ of urban women and $377(95.7 \%)$ of rural women were housewives. (Table - 1)

Table 1. Socio-demographic characteristics of respondents in Assosa District, Assosa Zone, Benishangul Gumuz Region, Western-Ethiopia, May 2012

\begin{tabular}{|c|c|c|}
\hline Variables & & Number $(\%)(\mathrm{N}=525)$ \\
\hline \multirow{3}{*}{ Age } & $15-19$ & $18(3.4 \%)$ \\
\hline & $20-34$ & $433(82.5 \%)$ \\
\hline & $35-49$ & $74(14.1 \%)$ \\
\hline \multirow{3}{*}{ Religion } & Orthodox & $120(22.9 \%)$ \\
\hline & Muslim & $388(73.9 \%)$ \\
\hline & Others * & $17(3.3 \%)$ \\
\hline \multirow{4}{*}{ Ethnicity } & Berta & $303(57.7 \%)$ \\
\hline & Oromo & $39(7.4 \%)$ \\
\hline & Amhara & $158(30.1 \%)$ \\
\hline & Other $* *$ & $25(4.7 \%)$ \\
\hline \multirow{5}{*}{$\begin{array}{l}\text { Educational } \\
\text { Status }\end{array}$} & Unable to read \& write & $285(54.3 \%$ \\
\hline & Able to read \& write & $127(24.2 \%)$ \\
\hline & $1-6$ grade & $24(4.6 \%$ \\
\hline & 7-12 Grade & $55(10.5 \%)$ \\
\hline & College or university & $34(6.5 \%)$ \\
\hline \multirow{4}{*}{ Marital Status } & Married & $476(90.7 \%)$ \\
\hline & Divorced & $7(1.3 \%)$ \\
\hline & Widowed & $2(0.4 \%)$ \\
\hline & Single & $40(7.6 \%)$ \\
\hline \multirow{4}{*}{ Occupation } & House wife & $451(85.9 \%)$ \\
\hline & Gov’t Employed & $32(6.1 \%)$ \\
\hline & Student & $25(4.8 \%)$ \\
\hline & Others*** & $17(3.3 \%)$ \\
\hline
\end{tabular}




\subsection{Utilization of Family Planning Service}

Three hundred eleven $(78.9 \%)$ of rural women had ever used family planning service. Majority $288(92.6 \%)$ of the women ever used injectable followed by pills $146(46.9 \%)$. However, 111(84.7\%) urban women had ever used at least one method of family planning service. Most 93(83.8\%) urban women ever used injectable followed by pills 22(19.8\%). Three hundred thirty nine $(64.6 \%)$ women were using family planning methods at the time of the survey (97(74.1\%) for urban and 242(61.4\%) for rural). Among the types of family planning methods, $268(78.8 \%)$ women used injectable frequently (74(76.3\% for urban and 194(80.2\% for rural) followed by Norplant 41(12.1\%), \{9(9.3\% for urban and $32(13.2 \%)$ for rural $\}$. Women from urban area were more likely to receive family planning from health facility than women from rural area. (Table - 2)

Table 2. Family planning service practice of respondents in Assosa District, Assosa zone, Benishangul Gumuz Region, West Ethiopia, May 2012.

\begin{tabular}{|c|c|c|c|c|}
\hline \multirow{3}{*}{ Variables } & & \multicolumn{2}{|c|}{ Place of residence } & \multirow{2}{*}{ Total $(\mathrm{N}=\mathbf{5 2 5})$} \\
\hline & & Urban $(n=131)$ & Rural (n=394) & \\
\hline & & No (\%) & No (\%) & No (\%) \\
\hline \multirow{2}{*}{ Health facility gives family planning services } & Yes & $119(90.8 \%)$ & $384(97.5 \%)$ & $503(95.8 \%)$ \\
\hline & No & $12(9.2 \%)$ & $10(2.5 \%)$ & $22(4.2 \%)$ \\
\hline \multirow{2}{*}{ Ever use family planning service } & Yes & $111(84.7 \%)$ & $311(78.9 \%)$ & $422(80.4 \%)$ \\
\hline & No & $20(15.3 \%)$ & $83(21.1 \%)$ & $103(19.6 \%)$ \\
\hline \multirow{6}{*}{ Type of family planning methods ever used ( $\mathrm{n} 1=111, \mathrm{n} 2=311)$} & Condom & $1(0.9 \%)$ & $6(1.9 \%)$ & $7(1.6 \%)$ \\
\hline & Pills & $22(19.8 \%)$ & $146(46.9 \%)$ & $168(39.8 \%)$ \\
\hline & Injectable & $93(83.8 \%)$ & $288(92.6 \%)$ & $381(90.3 \%)$ \\
\hline & IUCD & $2(1.8 \%)$ & $7(2.2 \%)$ & $9(2.1 \%)$ \\
\hline & Norplant & $4(3.6 \%)$ & $41(13.2 \%)$ & $50(11.8 \%)$ \\
\hline & Female sterilization & $0(0.0 \%)$ & $1(0.3 \%)$ & $1(0.2 \%)$ \\
\hline \multirow{2}{*}{ Current use of family planning service } & Yes & $97(74.1 \%)$ & $242(61.4 \%)$ & $339(64.6 \%)$ \\
\hline & No & $34(25.9 \%)$ & $152(38.6 \%)$ & $186(35.4 \%)$ \\
\hline \multirow{5}{*}{$\begin{array}{l}\text { Type of family planning method using currently } \\
(\mathrm{n} 1=97, \mathrm{n} 2=242)\end{array}$} & Condom & $3(3.1 \%)$ & $2(0.8 \%)$ & $5(1.5 \%)$ \\
\hline & Injectable & $74(76.3 \%)$ & $194(80.2 \%)$ & $268(78.8 \%)$ \\
\hline & IUCD & $2(2.1 \%)$ & $3(1.2 \%)$ & $5(1.5 \%)$ \\
\hline & Norplant & $9(9.3 \%)$ & $32(13.2 \%)$ & $41(12.1 \%)$ \\
\hline & Pill & $10(10.3 \%)$ & $11(4.5 \%)$ & $21(6.2 \%)$ \\
\hline
\end{tabular}

\subsection{Reasons for Utilization of Family Planning Methods}

Reasons forwarded by respondents for using family planning methods include: $285(84 \%)$ to space the birth interval $\{76(78.3 \%)$ for urban and $209(86.4 \%$ for rural $\}$; $145(42.8 \%)$ to prevent unwanted pregnancy $\{56(57.7 \%$ for urban and $89(36.8 \%)$ for rural $\}$ and $62(18.3 \%)$ to promote health of born child $\{14(14.4 \%$ for urban and $48(19.8 \%)$ for rural $\}$. (Table -3$)$

Twenty four years old Health Extension Worker; "Women in the kebele were use different method of family planning method like injectable, Pills, Norplant, IUCD, and condom." The Group of community leaders and religious leaders; "The advantages of family planning were increase family income and promote health of child and mothers. However, the disadvantages of family planning methods were causing undergrowth of the child, exposed to the diseases, and the long term family planning methods were cause infertility and sterility".

\subsection{Reasons for Non-Utilization of Family Planning Methods}

The reasons for non-utilization of family planning methods among women are summarized under the following four headings.

\subsubsection{Fertility Related Reasons}

Fertility related reasons were the most reported reasons that affected family planning services utilization among participants. Among fertility related reasons, 37(46.8\%) women mentioned breast feeding $\{7(38.9 \%$ for urban and $30(49.2 \%)$ for rural $\}$ while $17(21.5 \%)$ mentioned no having sex $\{6(33.3 \%$ for urban and $11(18 \%)$ for rural $\}$.

\subsubsection{Oppositions to Use}

Opposition is also another reason reported by women for not utilizing. These reasons include: women who did not want to use family planning methods due to their own personal opposition contributed to $67(73.6 \%)$ of non-users $\{6(66.7 \%$ for urban and $61(74.4 \%$ for rural $\}$ and $7(7.7 \%)$ reported that they have faced oppositions from husbands/partners all of them are in rural area. Religious opposition also appeared to be important barrier to non-use of family planning methods which accounted for $15(16.5 \%)$ of the nonusers $\{2(22.2 \%$ for urban and $13(15.9 \%)$ for urban $\}$

\subsubsection{Method Related Reasons}

Sometimes potential family planning users prefer not to use more reliable methods due to misconception and concerns about their health. The method related reasons include: $22(55 \%)$ fear of side effects $\{5(62.5 \%$ for urban and $17(53.1 \%)$ for rural $\}$ followed by $13(32.5 \%)$ health concern 
$\{1(12.5 \%)$ for urban and $12(37.5 \%)$ for rural $\}$.

\subsubsection{Knowledge of Method and Source}

The knowledge and sources of information on family planning methods were other important factors for nonutilization of family planning. Lack of knowledge of family planning methods accounted $35(97.3 \%)$ of non-users $\{8(100 \%)$ for urban and $28(96.6 \%)$ for rural $\}$. (Table - 3 )
A health worker whose age is 29 years old; "ANC service were utilized in the good manner but women were not using the family planning service especially in rural areas and Berta ethnic group were not also using family planning methods because they state that the child is a gift of the "God" or "Alah" so that no need of using a family planning methods and it is unacceptable".

Table 3. Reason for utilization and non-utilization of family planning methods in Assosa District, Assosa zone, Benishangul Gumuz Region, West Ethiopia, May 2012.

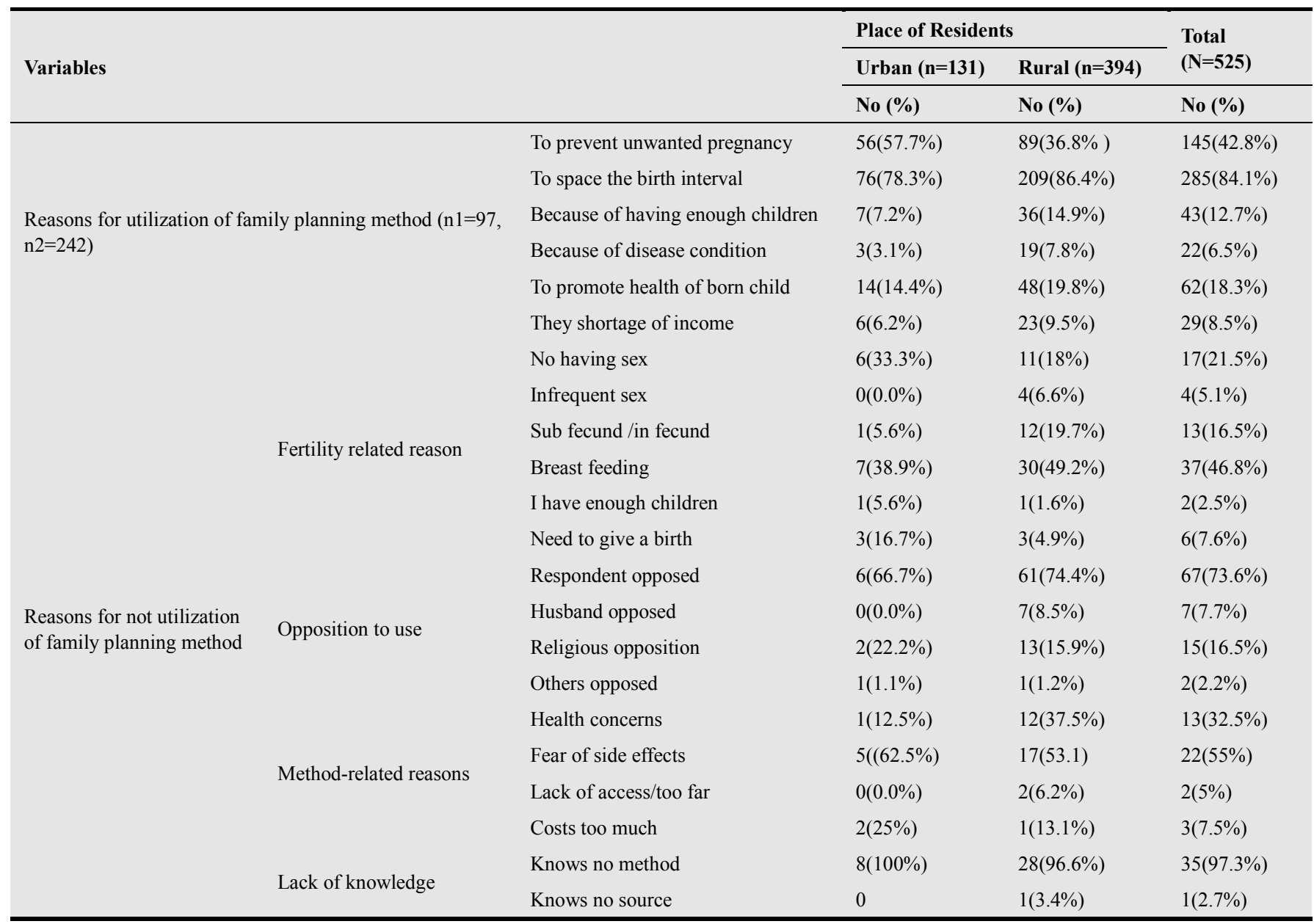

\subsection{Factors Influencing Utilization of Family Planning Services}

Bi-variate analyses involving all variables were performed to identify candidate variables for multivariate analysis for the family planning service utilization. Consequently, place of residence, maternal education, occupational status, ever had abortion, knowledge on (PNC, family planning and maternal health care service), attitude towards delivery, attitude towards family planning service and availability of family planning service were showed a significant association $(p<0.05)$ with utilization of family planning service.

A multivariate analysis was performed for identified candidate variables for the utilization of family planning service in bi-variate analysis which showed a significant association. Accordingly maternal educational status, knowledge on family planning services, attitude towards family planning service and availability of family planning service were showed significant association on multivariate analysis.

Women who attended $>=7$ th grade were 2.19 times more likely to use family planning methods currently than illiterate women $[\mathrm{AOR}=2.19,95 \%$ CI: 1.11, 4.33]. Women who were knowledgeable on family planning service were 3.39 times more likely to receive family planning service currently than their counter parts [AOR=3.39 95\%CI: $1.36,8.48]$.

Women who had favourable attitude towards family planning service were 2.16 times more likely to receive family planning service currently than women who had unfavorable attitude [AOR=2.16 95\%CI: 1.45-3.23]. However, women for whom family planning service was 
available in their kebele were 4.33 times more likely to use

$[\mathrm{AOR}=4.33,95 \% \mathrm{CI}: 1.5,12.46] .($ Table -4$)$ family planning service currently than their counter parts

Table 4. Factors influencing utilization of family planning services in Assosa District, Assosa Zone, Benishangul Gumuz Region, Western-Ethiopia, May 2012.

\begin{tabular}{|c|c|c|c|c|c|}
\hline \multirow{2}{*}{ Variables } & & \multicolumn{2}{|c|}{ Family planning service utilization } & \multirow{2}{*}{$\begin{array}{l}\text { Crude } \\
\text { OR }(95 \% \mathrm{CI})\end{array}$} & \multirow{2}{*}{$\begin{array}{l}\text { Adjusted } \\
\text { OR(95\%CI) * }\end{array}$} \\
\hline & & No & Yes & & \\
\hline \multirow{3}{*}{ Place of residence } & Urban & $34(26 \%)$ & $97(74 \%)$ & 1 & \\
\hline & Rural & $152(38.5 \%)$ & $242(61.4 \%)$ & $0.56(0.36-0.87)$ & $1.02(0.49-2.11)$ \\
\hline & Illiterate & $127(44.6 \%)$ & $158(55.4 \%)$ & 1 & \\
\hline \multirow{3}{*}{ Educational status } & Able to read and write & $35(27.6 \%)$ & $92(72.4 \%)$ & $2.11(1.34-3.33)$ & $1.43(0.88-2.33)$ \\
\hline & $1-6$ th Grade & $9(37.5 \%)$ & $15(62.5 \%)$ & $1.34(0.56-3.16)$ & $0.85(0.31-2.36)$ \\
\hline & $>=7$ th Grade & $15(16.9 \%)$ & $74(83.1 \%)$ & $3.96(2.17-7.24)$ & $2.19(1.11-4.33)$ \\
\hline \multirow{2}{*}{ Occupation status } & House wife & $173(38.4 \%)$ & $278(61.6 \%)$ & 1 & \\
\hline & Others & $13(17.6 \%)$ & $61(82.4 \%)$ & $2.92(1.56-5.47)$ & $1.96(0.89-4.28)$ \\
\hline \multirow{2}{*}{ Ever had abortion } & No & $158(33.8 \%)$ & $310(66.2 \%)$ & 1 & \\
\hline & Yes & $28(49.1 \%)$ & $29(50.9 \%)$ & $0.53(0.3-0.9)$ & $0.59(0.33-1.09)$ \\
\hline \multirow{2}{*}{ Knowledge on PNC service } & Not knowledgeable & $170(37.9 \%)$ & $278(62.1 \%)$ & 1 & \\
\hline & Knowledgeable & $16(20.8 \%)$ & $61(79.2 \%)$ & $2.33(1.3-4.17)$ & $0.43(0.12-1.57)$ \\
\hline \multirow{2}{*}{ Knowledge on F/P service } & Not knowledgeable & $180(38.9 \%)$ & $283(61.1 \%)$ & 1 & \\
\hline & Knowledgeable & $6(9.7 \%)$ & $56(90.3 \%)$ & $5.94(2.51-14.06)$ & $3.39(1.36-8.48)$ \\
\hline \multirow{2}{*}{ Knowledge on maternal health } & Not knowledgeable & $173(39.4 \%)$ & $266(60.6 \%)$ & 1 & \\
\hline & Knowledgeable & $13(15.1 \%)$ & $73(84.4 \%)$ & $3.65(1.96-6.79)$ & $3.0(0.73-12.34)$ \\
\hline \multirow{2}{*}{ Attitude towards delivery service } & Unfavourable attitude & $59(45.4 \%)$ & $71(54.6 \%)$ & 1 & \\
\hline & Favourable attitude & $127(32.2 \%)$ & $268(67.8 \%)$ & $1.75(1.17-2.63)$ & $1.19(0.75-1.88)$ \\
\hline \multirow{2}{*}{ Attitude towards family planning } & Unfavourable attitude & $93(50.5 \%)$ & $91(49.5 \%)$ & 1 & \\
\hline & Favourable attitude & $93(27.3 \%)$ & $248(72.7)$ & $2.72(1.87-3.96)$ & $2.16(1.45-3.23)$ \\
\hline \multirow{2}{*}{$\begin{array}{l}\text { Availability of family planning } \\
\text { service }\end{array}$} & Not-available & $15(68.2 \%)$ & $7(31.8 \%)$ & 1 & \\
\hline & Available & $171(34 \%)$ & $332(66 \%)$ & $4.16(1.66-10.4)$ & $4.33(1.5-12.46)$ \\
\hline
\end{tabular}

* Adjusted for socio-demographic variable, obstetric characteristic, available of TTBA, knowledge, attitude and availability of service.

Bold indicates statistical significant at $\mathrm{p} . \mathrm{v}=0.05$.

\section{Discussion}

Family planning (FP) could prevent as many as one in every three maternal deaths by allowing women to space birth, avoid unintended pregnancies and abortion. This study reveals that current utilization of family planning methods $(64.6 \%)$ in district, among different method injectable (78.8\%). Even though, utilization of family planning service in the urban area (74\%) higher than as compared to rural area $(61.4 \%)$ due to urban women were know and had good perception on the important of family planning service. This result higher than study done in Mojo town in 2011 (38.3\%), study conducted in soda town $2005(43 \%)$ among current practice of contraceptive injectable (53.8\%) (9). In this study area they gain more information and awareness on family planning services from the health worker and health extension workers (HEW). However, community having misconception on long term family planning which said that it cause sterility and infertility and on condom which said that those who carry condom considered as prostitution.

Women who were attended $>=7$ th grade were 2.19 times more likely to use family planning methods currently than illiterate women. This finding in the line with study done in Mojo town revealed that women's literacy status significantly affected the chance of family planning service utilization: literate women are 1.903 times more likely to use family planning service than illiterate ones. And other study conducted in Turkey also indicated that woman with completed primary school has a nearly 30 percentage point higher probability of being aware of one of the two main prevention methods than a woman with no education $(9,10)$. This is due to the fact that education is means of gaining information on important of maternal health care service especially family planning services and decided to utilize the services.

Women who were knowledgeable on family planning service were 3.39 times more likely to receive family planning service currently than not knowledgeable ones. This result in the line with study conducted in Mojo Town 2009 reveals that knowledge on family planning methods were important factors for non-utilization of family planning service. That is, lack of knowledge on family planning methods accounted $6.5 \%$ for non-user of family planning service (9). This is due to the fact that women who had knowledge on the important and effect of family planning method she could decide easily to use the service.

However, availability of the family planning service in the kebele was 3.33 times likely to use family planning service currently than in counterpart. This result is in the line with WHO 2006 reveals that accessibility of health services have been shown to be an important determinant of utilization of family planning services in developing countries including Ethiopia and other Study done in India has shown that the distance from health facility directly affected the attendance of women for maternal health care services especially family planning services $(11,12)$.

Attitude of the community toward family planning service was the most important determinate factors in order to improve the utilization of the services. So, this study reveals that women who had favorable attitude towards family 
planning service were 2.16 times more likely to receive family planning service currently than in counterpart. Similar study conducted in Nigeria showed that women who approved family planning services were 6 times more likely to use family planning services than women who disapproved to use method. In addition, men often have positive attitudes towards family planning, but women believe that their husband disapproves of family planning, and hence do not want to use family planning (13).

Similarly the study in Turkey in 2006 revealed that women who approved of family planning are 6.3 times more likely to use a the impact of spousal communication and approval of family planning methods are particularly pronounced when the respondents have approved of family planning methods (14). Other Studies showed that women who discuss about family planning issues with their husbands/partners were 9.6 times more likely to utilize family planning services (15).

Conversely, utilization of contraceptives is much higher among women who believed that their husbands support the use of family planning (13). Similarly, a study in Tigray region reveals women who had frequent discussion with their partners were more likely to utilize family planning services (9). A study conducted in Kenya reported that husband -wife communication, particularly the wife's perception of her husband's approval of family planning, was highly associated with current contraceptive use (15). The fact that discusses and communicates with their partner on family planning method is very essential to alleviate the misconception on the uptake of contraceptive methods.

\section{Conclusion and Recommendation}

In general this study tried to reveal that there was a low utilization family planning service in the study area as compared with national health indicators of HSDP IV. Some of the respondents state that the reasons for using family planning method were to space the birth interval, to prevent unwanted pregnant and having enough children. However, various reasons for non-utilization of family planning methods such as fertility related reason, opposition to use method related reason and lack of knowledge. In the study area different factors were identified that influence utilization of family planning services such as place of residence, educational status, knowledge on family planning, attitude toward family planning and availability of family planning services.

Therefore, Ministry of health, regional health bureau and their partners should expand family planning services and fulfill the material or equipment in the health facility in the study area and expand equipped health facility for the provision of family planning service in study area. In addition increase women's autonomy within the family, enhancing their ability to earn and control over the utilization of family planning services and decide on their own health. Regional health bureau and different partners should providing adequate Information, Education and communication (IEC) on family planning services in order to bring good knowledge as well as behavioural change to the community.

\section{Limitation of the Study}

Since data collectors were health extension workers working in the study area social desirability bias was expected to occur. As the study considered events occurred in the past five years recall bias might occur. Because of its cross-sectional nature, the study may not show temporal relation.

\section{Abbreviation \\ AOR: Adjusted Odd Ratio \\ EDHS: Ethiopia Demographic Health Survey \\ FGD: Focus Group Discussion \\ FP: Family Planning \\ HEW: Health Extension Workers \\ HSDP: Health Sector Development Program \\ IEC: Information Education Communication \\ IUCD: Intrauterine Copper Device \\ PNC: Post Natal Care \\ WHO: World Health Organization}

\section{Acknowledgment}

All staffs of Department of Population and Family Health in Jimma University deserve my deepest appreciation for their cooperation. I would also like to thank Benishangul Gumuz Regional Health Bureau for their financial support and cooperation that facilitated the study process.

I would also thank all supervisor and data collectors for their genuine gathering consistent and reliable information that helps for analysis and report of research thesis. Last but not least I am highly indebted to my wife Abebech Tefera and my son Nahom Muluwas who had taken the whole responsibility managing the family and be silence during my course respectively.

\section{References}

[1] M. Chatterjee, "Indian Women, Their Health and Economic Productivity," World Bank Discussion Paper; 109. Washington, D.C.1990.

[2] H. Carl, MK. Mary, "World Population Data Sheet," Washington D.C. Population Reference Bureau, 2008.

[3] S. Rhoda, A. Lori, G. Jay, C. Donna, "Family Planning Saves Lives," Population Reference Bureau, 4th Ed. USA. 2009

[4] Central Bureau of Statistics, "Kenya Demographic and Health Survey 2003," Calverton, Maryland: CBS, MOH and ORC Macro, 2003.

[5] M. Borda, "Family planning needs during the First Year Postpartum," Unpublished paper, ACCESS-FP Project, Jhpiego, Baltimore, USA, 2006. 
[6] Central Statistical Agency of Ethiopia and ORC Macro, "Ethiopia Demographic and Health Survey 2005," Addis Ababa, Ethiopia and Calverton, Maryland, USA: Central Statistics Agency and ORC Macro, 2006.

[7] Central Statistical Agency of Ethiopia and ORC Macro, "Ethiopia Demographic and Health Survey 2011," Addis Ababa, Ethiopia and Calverton, Maryland, USA: Central Statistics Agency and ORC Macro, 2011.

[8] UNFPA, "Maternal Health Care Seeking Behavior in Ethiopia," In-depth Analysis of the Ethiopian Demographic and Health Survey 2005. Ethiopian Society of Population Studies. Addis Ababa, October 2008

[9] Abebe Gizaw and Nigatu Regassa; Family planning service utilization in Mojo town, Ethiopia: Journal of Geography and Regional Planning. June 2011; 4(6), pp. 355-363,

[10] JT. Bertrand, E. Seiber, G. Escudero, "Contraceptive dynamics among the Mayan population of Guatemala:1978-1998,"
Chapel Hill, North Carolina, University of North Carolina at Chapel Hill, Carolina Population Center [CPC].2000.

[11] World Health Organization (WHO), "Standards for maternal and neonatal care," Geneva. WHO, 2006.

[12] Deki, "Utilization of Maternal Health Care Services in Sikkim, India, International Institute for Population Sciences, April, 2005. (Unpublished Student's Seminar Paper).

[13] BJ. Feyisetan, S. Bamiwuye, "Postpartum Counseling and Contraceptive Use in Nigeria," Soc. Sci. Rev., 15(1), pp.30-41, 1998.

[14] A. Ozlem, F. Hatice, "On the use of contraceptive methods among married women in Turkey," Eur. J. Contraception Reproductive Health Care, 11(3), pp. 228-236, 2006.

[15] A. Lasee, S. Becker, "Husband wife communication about family planning and contraceptive use in Kenya," Int. Family Planning Perspective, 23(15), pp.20-33, 1997. 